\section{La producción de conocimiento antropológico desde la extensión. Colaboración con poblaciones indígenas de la provincia de Buenos Aires y Norpatagonia, Argentina}

\author{
Juan Manuel Engelman \\ Consejo Nacional de investigaciones \\ Científicas y Técnicas / Universidad de \\ Buenos Aires. \\ Universidad Nacional de Luján, Argentina. \\ jmengelman@hotmail.com \\ (iD) orcid.org/0000-0002-9642-4945 \\ Sofía Varisco \\ Fondo para la Investigación Científica y \\ Tecnológica. Universidad Nacional de Luján /
}

\author{
Universidad de Buenos Aires. \\ sofiavarisco705@hotmail.com \\ iD orcid.org/0000-0003-0688-6706

\section{Sebastián Valverde} \\ Consejo Nacional de investigaciones Científicas \\ y Técnicas / Universidad de Buenos Aires. \\ Universidad Nacional de Luján, Argentina. \\ sebavalverde@yahoo.com.ar \\ (iD) orcid.org/0000-0002-8275-1734
}

RECEPCIÓN: 28/05/20

ACEPTACIÓN FINAL: 13/07/20

\section{Resumen}

La extensión universitaria, en los últimos años, adquirió una mayor institucionalización gracias a la creación de oficinas de extensión en múltiples universidades nacionales y a su implementación como parte de la currícula en el grado. Estos nuevos escenarios nos interpelan a repensar el lugar que cumple la extensión en relación la investigación y la producción de la teoría antropológica.

El presente trabajo tiene por objetivo analizar el vínculo entre dos campos que desde la tradición academicista del campo antropológico se piensan como separados (lo académico y la extensión); desde una mirada que se focaliza en su articulación y considera el contexto de producción del conocimiento como resultado de la colaboración y la demanda intercultural. Llevaremos adelante dicha reflexión la mediante la descripción de tres experiencias de trabajo con pueblos indígenas de la Región Metropolitana de Buenos Aires, la localidad de Carhué - provincia de Buenos Aires-y la región de los lagos en Norpatagonia — provincias de Río Negro y Neuquén.

Palabras clave: pueblos indígenas; extensión universitaria; academia; Estado; intercultural.
The production of anthropological knowledge from extension. Collaboration with indigenous populations in the province of Buenos Aires and Norpatagonia, Argentina

\section{Abstract}

In the recent years, the university extension has become more institutionalized thanks to the creation of extension offices into a multiple national universities and because its implementation as part of the curriculum degree. This new scenario, of academic training, challenge us to rethink socia anthropology, in relation to the investigation and the production of theory. This work seeks to analyze the relationship between two fields of anthropological work usually thought as separate into the academicist tradition (academic and extension); from a perspective that focuses on its articulation and considers the context of knowledge production as a result of collaboration and intercultural demand. We will carry out this reflection by describing three work experiences with indigenous peoples of the Metropolitan Region of Buenos Aires, the town of Carhué - province of Buenos Aires- and the region of lakes in Norpatagonia - provinces of Río Negro and Neuquén.

Keywords: indigenous peoples; university extension; academy; state; intercultural.
A produção de conhecimento antropológico a partir da extensão. Colaboração com populações indígenas na província de Buenos Aires e Norpatagonia, Argentina

Resumo

A extensão universitária, nos últimos anos, tornou-se mais institucionalizada, graças à criação de escritórios de extensão em várias universidades nacionais e à sua implementação como parte do currículo do curso. Esses novos cenários nos desafiam a repensar o lugar que a extensão desempenha em relação à pesquisa $e$ produção da teoria antropológica. O objetivo deste trabalho é analisar a relação entre dois campos que, a partir da tradição acadêmica do campo antropológico, são considerados separados (o acadêmico e a extensão); de uma perspectiva que se concentra em sua articulação e considera o contexto da produção do conhecimento como resultado da colaboração e da demanda intercultural. Realizaremos essa reflexão descrevendo três experiências de trabalho com os povos indígenas da Região Metropolitana de Buenos Aires, a cidade de Carhué - província de Buenos Aires- e a região dos lagos da Norpatagonia —províncias de Río Negro e Neuquén.

Palavras-chave: povos indígenas; extensão universitária; academia; Estado; intercultural.

Para citación de este artículo: Engelman, J. M.; Varisco, S. y Valverde, S. (2020). La producción de conocimiento antropológico desde la extensión. Colaboración con poblaciones indígenas de la provincia de Buenos Aires y Norpatagonia, Argentina. +E: Revista de Extensión Universitaria, 10(13), e0001. doi: 10.14409/extension.2020.13.Jul-Dic.e0001 


\section{Introducción}

Con frecuencia, en diversos contextos institucionales donde se debate la práctica antropológica surge una distinción entre aquello que entendemos como "académico" y lo que entendemos como "extensionista". Pero ocurre que en ocasiones las y los antropólogos -y demás cientistas sociales- llevamos adelante nuestra labor cotidiana en la intersección del campo académico y el campo constituido por los vínculos y procesos que investigamos. Consideramos, con Zenobi, que en ambos casos se trata de relaciones personales e institucionales a través de las cuales producimos conocimiento que es usado, evaluado, ponderado, criticado, defendido, atacado, por diferentes actores que forman parte de esos campos (Zenobi, 2019, p. 60). Ahora bien, distinguir la complejidad de escenarios y actores nos permite repensar la multiplicidad de expresiones que refleja tanto la práctica como la reflexión teórica en la antropología reciente. En las siguientes páginas proponemos describir un conjunto de formatos de trabajo que han definido y constituido gran parte de nuestra formación. A su vez, partimos de considerar que encorsetar o compartimentar el carácter procesual de nuestra labor en categorías tales como "académico" y "extensión" no hace más que legitimar un falso opuesto altamente naturalizado al interior de nuestra disciplina.

En trabajos recientes hemos comentado que nuestra propuesta teórico-metodológica de investigación-intervención procura aunar las tareas y formación de tesistas, becarios y becarias, investigadores e investigadoras a partir de la realización de actividades de extensión y divulgación en articulación con nucleamientos ${ }^{1}$ y comunidades indígenas en el ámbito de la Región Metropolitana de Buenos Aires (RMBA), el interior de la provincia de Buenos Aires (Carhué) y Norpatagonia. En esta línea, destacamos la relevancia de la extensión universitaria como parte fundamental del ejercicio crítico y, particularmente, antropológico. Hacemos hincapié en ello porque al menos hoy en día nuestras investigaciones o líneas de acción/ intervención surgen de necesidades o reclamos particulares expresados por los mismos sujetos que articulan con el equipo en el marco de diversos proyectos en curso. ${ }^{2}$ Estas experiencias devienen de interpelaciones específicas cuyos objetivos fueron dialogados con la diversidad de sujetos bajo la premisa del respeto y de la mutua colaboración, es decir, en el marco del Consentimiento Libre Previo e Informado (CLPI), lo que a nuestro juicio valida los resultados esperados y además permite que el trabajo antropológico acompañe a la población y no se posicione de manera externa.

"Por lo tanto, no se trata de exponer un conjunto de resultados o descripciones neutralmente valorativos, sino de fortalecer las relaciones y compromisos que los diversos grupos tienen en lo local a modo de garantizar condiciones positivas para su visibilización —como es en el caso étnico- y negociación con distintas instancias políticas y universi-

1) Liliana Tamagno propone la noción de "nucleamiento" para referirse al proceso migratorio de la población indígena y a su capacidad de nuclearse, en la medida en que las condiciones materiales lo permitan, en espacios geográficamente diferentes y lejanos a los de origen (2014). De este modo, la presencia indígena en la ciudad se torna en un estudio amplio y abarca una gran cantidad de aspectos históricos de la vida familiar, organización, desplazamiento, trabajo, participación, ingresos, vivienda, educación, salud, territorio e identidad, de una diversidad de pueblos originarios que arribaron a tejidos sociales más heterogéneos que los de origen.

2) Proyecto de Extensión Universitaria UBANEX 11va. convocatoria "Consolidando las prácticas sociales educativas" (2019-2021), titulado "Indígenas en la ciudad: visibilización y organización en el marco de las transformaciones recientes", radicado en la Secretaría de Bienestar y Extensión Universitaria, Facultad de Filosofía y Letras, Universidad de Buenos Aires (UBA); dirigido por el Dr. Sebastián Valverde y codirigido por el Dr. Juan Carlos Radovich. 
tarias. Lo que se asume, pues, es un campo complejo de relaciones del cual no se puede estar exento ya que, en muchos casos, irrumpimos en él como investigadores y no como sus creadores, como se pensó durante largo tiempo". (Romero et al., 2016, p. 340)

Esta práctica profesional que se nutre de un tejido vincular e institucional cambiante es parte de ciertos aspectos que no se mantienen a lo largo del tiempo sino que son un producto histórico generado al interior de una determinada comunidad científica. Ejemplo de ello es la existencia de líneas de trabajo antropológico -insertadas en otros espacios institucionales- que, al igual que nuestro equipo, comparten interrogantes y abordajes teóricos y prácticos al respecto. El grupo de investigación que dirige Liliana Tamagno (Tamagno et al., 2005) y Carolina Maidana (2019) en la Universidad Nacional de La Plata ha elaborado varias contribuciones acerca de la importancia que tiene romper con ciertas categorías analíticas cuando se trata de trabajar con poblaciones indígenas en la ciudad. La reflexión epistemológica de la que parten sus planteos contribuye a redefinir las metodologías de trabajo al destacar el carácter intersubjetivo del conocimiento a partir de la colaboración "con" los sujetos y no "para" los sujetos. ${ }^{3}$ En la misma línea, Daniel Mato propone que "es ética, política y epistemológicamente imperativo que los investigadores hallen maneras de promover la incorporación consciente de los grupos sociales en las agendas de investigación" (2014, p. 240). En otras palabras, se trata de inaugurar un tipo de relación social diferente. Los sujetos con que trabajamos no son meros informantes, sino que hacemos nuestra labor antropológica con interlocutores que pertenecen a las sociedades que interrogamos (Bartolomé, 2003). En definitiva, lo que se busca es un diálogo intercultural superador de las relaciones de poder involucradas en la investigación (Cardoso de Oliveira, 1998).

Por lo visto, a lo largo de las últimas décadas múltiples posturas analíticas buscan subvertir uno de los principios clásicos de la antropología social, el que solemos naturalizar durante nuestra propia formación de grado. Hablamos de aquel criterio epistemológico que sustenta y legitima que la antropología es el estudio del "Otro" — con mayúscula - a partir del "Nosotros —también con mayúscula- (Engelman, 2014). El distanciamiento físico y cultural se vuelve una herramienta prototípica mediante la cual construimos el comportamiento y definimos las pautas culturales y relaciones de aquellos grupos de personas que supuestamente asumimos como diferentes de nosotros y nosotras. Resulta frecuente encontrar menciones, listados o reconocimientos a los informantes que ayudaron a construir y a definir las ideas en la escritura de artículos y libros. Esto se debe a que durante mucho tiempo se ha aceptado, al interior de la comunidad profesional, la utilización de gentes de los pueblos en los que trabajamos como meros instrumentos destinados a ser manipulados dentro de las técnicas de recolección de datos (Bartolomé, 2003). Sin embargo, este artículo busca reposicionar

3) En el año 2019 Liliana Tamagno participó en un ciclo de entrevistas organizado por la Sociedad Argentina de Antropología (SAA) en el Museo Etnográfico Juan B. Ambrosetti, pertenenciente a la Facultad de Filosofía y Letras (UBA), en la Ciudad Autónoma de Buenos Aires. En esa ocasión no solo argumentó la necesidad de repensar el uso antropológico del concepto de "comunidad" para evitar esencializaciones sino que hizo énfasis en recordar que debemos evitar en nuestros textos el término "vulnerables" porque alude de alguna manera a una condición intrínseca de los pueblos cuyos derechos son constantemente vulnerados y no permite valorar su capacidad de organización y resistencia (Sociedad Argentina de Antropología, 2019). Entrevista disponible en: https://www.youtube.com/watch?v=94oTb3YscO8 
el lugar de los informantes como interlocutores para orientar nuestra labor antropológica en un campo del saber que surge de la configuración de culturas diferentes y que defiende la creación de argumentaciones interculturales. El objetivo no es buscar aquello que diferencia sino lo que se comparte para repensar lo étnico en el mundo contemporáneo y, así, estimular, más allá de su cosificación, formatos novedosos de relación y participación sociopolítica, económica y cultural de la diversidad en el marco de políticas públicas, la universidad y la multiplicidad de instituciones.

Otro aspecto a destacar de nuestras investigaciones tiene que ver con las condiciones materiales en que las llevamos adelante (Trinchero, 2007), así como las consecuencias que ello posee en la definición de objetivos de investigación, resultados, y de su posible cuantificación. ${ }^{4}$

\section{El contexto sociopolítico y la extensión universitaria}

Poder posicionarnos desde un lugar que articule el trabajo académico y de extensión universitaria es consecuencia de un contexto también particular de la práctica antropológica profesional. No podemos negar el impacto que en ello poseen distintos escenarios específicos.

El primero de ellos, de escala más global, tiene que ver con la incidencia de la sanción de leyes, la creación de organizaciones, comités, etc., que pretenden intervenir en el control y la certificación de diversos procesamientos éticos - y por extensión metodológicos- de las investigaciones desarrolladas en los campos científicos. La expansión de estas tecnologías, estructuras y agentes especializados en el tema es producto del "discurso de la investigación ética" que ha colonizado numerosas disciplinas y que ha sido interpretado como un instrumento de gubernamentalidad instalado en el seno de las comunidades científicas ${ }^{5}$ (Halse y Honey, 2007).

A partir de la crisis en todos los órdenes sociales que tuvo lugar en el año 2001 - con epicentro en las trágicas jornadas del 19 y 20 diciembre-, como resultado de la aplicación de políticas neoliberales (Petz, Hindi, Cervera Novo, Corbato y Giraudo, 2016), la universidad pública resultó fuertemente interpelada en sus misiones clásicas de docencia, investigación y extensión, en los años subsiguientes, y desde la implementación de políticas alternativas diferenciadas de la década anterior. En este nuevo contexto se valoró cada vez más su rol estratégico para el desarrollo nacional —al considerar su autonomía universitaria- y se pusieron cada vez más en discusión sus tradicionales definiciones de "excelencia" (en ocasiones ambiguas y discutibles) (Petz et al., 2016). Así comenzaron a instrumentarse diferentes programas, tanto desde el Ministerio de Educación de la Nación como desde las universidades nacionales, las que al verse desafiadas respecto de su relevancia social implementaron novedosos subsidios a la extensión universitaria (en el caso de la UBA, en el año 2004 em-

4) En los últimos años, en las ciencias sociales ha adquirido relevancia la noción de "impacto" en el interior de las comisiones de evaluación del Consejo Nacional de Investigaciones Científicas y Técnicas (CONICET) y en la aplicación de ciertas líneas de financiación de ciencia y técnica. Dicha noción busca implementar un conjunto de criterios que puedan medir y/o cuantificar — de forma arbitraria - el grado de impacto y transferencia que pueden tener las disciplinas sociales, las humanidades particularmente, con relación a los sujetos y al contexto donde desarrollan su labor. 5) Diego Zenobi menciona al respecto que ello es ejemplificado con el anonimato de la identidad de los interlocutores y el hecho de que brinden el consentimiento informado de su participación en la investigación (2019). 
pezaron los subsidios para el trabajo de extensión universitaria enmarcada en los proyectos UBANEX, algo que luego ampliaremos). El sentido de estos programas apuntó a la promoción de la vinculación territorial de la universidad, entendiendo que los saberes académicos constituyen un valor determinante para mejorar las condiciones de vida del conjunto de la sociedad, especialmente de los más humildes (Alonso, 2015). Este cambio sustancial fue factible gracias al incremento del presupuesto de educación impulsado en aquellos años por los gobiernos de Néstor Kirchner (2003-2007) y Cristina Fernández de Kirchner (2007-2011 y 2011-2015) ${ }^{6}$ y también por el impulso al desarrollo científico.

Se trata de diversas experiencias relacionadas con la denominada "movilización del conocimiento", desde el punto de vista crítico de Naidorf y Perrota (2015). La categoría de "movilización del conocimiento" surge en el año 2000, enmarcada en la discusión sobre la necesidad de que las políticas de investigación en ciencias sociales se ajusten a un nuevo requerimiento: contar con la producción de un tipo de conocimiento de lo social "listo para la acción". Esto implica ir más allá de la tradicional etapa de difusión; sería una función adicional del investigador en ciencias sociales encontrar caminos que enlacen la producción del conocimiento social con la utilización de ese mismo conocimiento social producido.

En un segundo escenario, la extensión universitaria en la Argentina varió según la trasformación de las universidades, la experiencia de los sujetos que allí se formaban y las demandas sociales. Con relación a este último punto, la Reforma Universitaria de Córdoba de 1918 es un antecedente importante dado que incluye la idea de la extensión universitaria aunque en general se continuó con la misma lógica tradicional durante muchos años (Varisco, 2020). En un plano más particular, localizamos la importancia que ha adquirido la labor extensionista en los últimos años gracias a la apertura de secretarías de extensión en distintas universidades nacionales. ${ }^{7}$ Cabe aclarar que hay experiencias previas, como es el caso de la Secretaría de Extensión de la Universidad Nacional del Litoral (UNL), una de las más antiguas del país que en 2019 cumplió 100 años y desde entonces data el trabajo de extensión, y el de la Facultad de Filosofía y Letras (FFyL-UBA), que en el año 1958 creó el Departamento de Extensión Universitaria.

Este camino más institucionalizado de la labor profesional en extensión no solo ha influenciado en los formatos y en la formación de las nuevas generaciones de tesistas, becarios, becarias, investigadores e investigadoras, sino que ha canalizado el otorgamiento de múltiples subsidios que contribuyen tanto a reproducir como a replicar dicha práctica.

6) En efecto, en 2003 el presupuesto del Ministerio de Educación era de 14500 millones de pesos (3,86 \% del PBI nacional). En 2012 llegaba a los 140611 millones de pesos (6,50 \% del PBI nacional). La Ley de Financiamiento Educativo 26.075 (LFE), que en diciembre de 2005 estableció la meta del $6 \%$ de inversión del PBI en materia de educación, ciencia y tecnología para 2010 (Petz et al., 2016). Un año más tarde, la Ley de Educación Nacional 26.206 (LEN) estableció que ese porcentaje debía ser destinado exclusivamente a la educación, mientras que ciencia y tecnología debían tener un presupuesto propio. Por otro lado, por aquellos años fueron fundadas más de 15 universidades nacionales -muchas de ellas en los municipios de la periferia de la provincia de Buenos Aires, en el denominado "Gran Buenos Aires"- con el objetivo de modificar la matriz elitista que caracterizó el acceso a las universidades nacionales (Petz et al., 2016).

7) Entre ellas podemos mencionar a la Universidad Nacional de Mar del Plata, la Universidad Nacional de General Sarmiento, la Facultad de Ciencias Políticas de la Universidad Nacional de Rosario, la Universidad Nacional de Avellaneda, La Universidad Nacional de La Plata y, con más de 100 años de experiencia, a la Universidad Nacional del Litoral (Lischetti y Petz, 2019). 
La extensión universitaria en los últimos años ha sido reconducida, se ha nutrido de nuevos contenidos y, de algún modo, ha recuperado el carácter contestatario que la caracterizó en sus inicios.

En parte, ello responde a la realización de congresos y planes de aplicación llevados adelante por la comisión de extensión universitaria del Consejo Interuniversitario Nacional (CIN), así como al énfasis que tales instancias han promovido acerca de la necesidad de insertar curricularmente las prácticas de extensión en la formación de grado (Lischetti y Petz, 2019).

Este contexto sociopolítico, que colabora en la producción de condiciones para el debate, es decir, para repensar las dimensiones constitutivas de los vínculos universidad-sociedad (Petz, 2015) permite diseños institucionales novedosos que replican discusiones y prácticas universitarias en ámbitos alejados de las mismas. La recepción de estas modalidades debe ser entendida a la luz de una gestión estatal que a lo largo de los últimos años ha incorporado demandas de los sectores populares en general e indígenas en particular. Nos referimos al impacto positivo de políticas estatales focalizadas en la recuperación y ampliación de derechos ciudadanos. Esto nos desafía a pensar, redefinir y llevar adelante tanto la función pública de la práctica antropológica —al interior de las universidades y de los organismos del Estado a los que pertenecemos- como la labor en articulación con los y las informantes al recepcionar sus demandas específicas en el plano local.

"Esta redefinición del modelo de universidad pública no pasa únicamente por la formación de profesionales más comprometidos, sino que involucra también una mirada sobre el lugar de la universidad en la sociedad, además de accionares posibles en los territorios de pertenencia". (Petz, 2015, p. 1).

El hecho de reparar y pensar el carácter político que posee la universidad con cuanto al territorio procura reforzar aquella metodología de trabajo colaborativa que introdujimos en las primeras líneas de trabajo. Las nuevas generaciones de investigadoras e investigadores somos conscientes de que llevamos adelante una labor desarrollada en relación con, y no desde la exterioridad. "Pensar la universidad en relación con es pensar a la universidad como actor social interviniente, como parte del territorio constituido y entrelazado por diferentes actores" (Petz, 2015, p. 1).

En el caso de quienes suscribimos este manuscrito, si nos detenemos a reflexionar acerca de cómo surgen varios de nuestros intereses, así como los trazos que encaminan nuestras investigaciones en curso - que luego se transforman en objetivos generales y particulares-, somos concluyentes al decir que provienen de la demanda de miembros que hoy en día constituyen las dirigencias indígenas urbanas, periurbanas y rurales. Actores con los que, junto a múltiples miembros de la sociedad indígena y no-indígena, organizaciones sociales, agencias estatales y privadas y movimientos indígenas, confluimos en laboratorios de socialización de saberes que nutren nuestra formación académica, de extensión y personal.

\section{Trabajo y experiencia del equipo}

Antes de avanzar en la descripción de los casos y la caracterización de los formatos y las relaciones que encaramos junto a los diversos nucleamientos y comunidades indígenas, 
deseamos referirnos, brevemente, a la labor que hemos desempeñado en los últimos años con la ejecución de una línea de financiamiento de la UBA mediante la convocatoria UBANEX (que ya mencionamos), que depende de la Secretaría de Extensión Universitaria y Bienestar Estudiantil (SEUBE) de la Facultad de Filosofía y Letras (FFyL).

Como punto de partida deseamos señalar que integramos el programa de investigación "Economía Política y Formaciones Sociales de fronteras: Etnicidades y territorios en redefinición" en el ámbito institucional de la FFyL de la UBA. Este programa surgió a fines de la década de 1990. En él confluyeron distintas líneas de investigación desarrolladas por diversos grupos que abordaban centralmente (pero no de manera exclusiva) la cuestión indígena. Dirigido por el Dr. Hugo Trinchero, el Dr. Juan Carlos Radovich y el Dr. Alejandro Balazote, el objetivo general del programa fue analizar los distintos relacionamientos que tenían los pueblos originarios con el Estado nacional, sus vinculaciones con los mercados, sus luchas políticas y sus formas organizacionales. En su inicio primó la concepción de que los pueblos originarios no eran "relictos del pasado" —como cierta antropología los imaginó- ${ }^{8}$ y que, lejos de estar al margen y constituirse como una externalidad del sistema económico, luchaban por sus derechos, por el control de los recursos económicos y por evitar la explotación que imponían los mecanismos de mercado. Estas temáticas, sin duda relevantes, no pueden ser pensadas desde la concepción de una universidad aislada del contexto en el que se inserta. Por ello, se parte de destacar que es la sociedad la que la financia y por lo tanto exige producir un conocimiento crítico, por un lado, y un marcado compromiso por parte de los y las investigadoras por el otro. En consecuencia y gracias a la apertura que produjo el mencionado programa en sus comienzos, resulta comprensible que paralelamente a las fuentes de financiación de ciencia y técnica más tradicionales se hayan llevado a cabo múltiples aportes con diversas experiencias de extensión y transferencia sin la asignación de recursos específicos. Hacemos mención a ello para dar cuenta de que el trabajo en colaboración y de extensión universitaria no surge de la financiación de organismos estatales o privados, sino que forma parte de la formación y compromiso de la antropología y del quehacer de nuestra disciplina desde hace varias décadas. ${ }^{9}$ No obstante, las primeras fuentes de financiación comienzan en el año 2006 con el Programa de Voluntariado Universitario del Ministerio de Educación ${ }^{10}$ y desde la cuarta convocatoria UBANEX del año 2012.

8) Alejandro Balazote y Mónica Rotman (2016) abordan tres tópicos de la perspectiva teórico-metodológica de Marcelo Bórmida: el tratamiento de lo económico, su concepción de la historia y el enfoque sobre el relacionamiento entre lo material y simbólico. Marcelo Bórmida fue una figura vinculada a las primeras décadas de la antropología en Argentina, quien marcara fuertemente su orientación, con actuación básicamente en contextos de gobierno de facto (2018). 9) Mirtha Lischetti cita uno de los pilares de la Universidad Latinoamericana innovada y reconfigurada a la extensión que surge de la Asamblea reunida en el Congreso de Estudiantes celebrado el 21 de junio de 1918 en la Universidad de Córdoba. "Este Congreso ha sancionado un voto, sabiamente redactado, en el sentido de difundir la extensión universitaria. Ha hecho lo que me proponía prestigiar, complentando este capítulo: vincular la universidad al pueblo" (Lischetti y Petz, 2019, p. 1).

10) Esta línea de financiación estuvo definida por tres proyectos: a) "Proyecto de fortalecimiento comunitario, rescate de la memoria y la identidad indígena" (2006-2008), b) "Patrimonio histórico-cultural y fortalecimiento comunitario en poblaciones indígenas mapuches y tobas" (2007-2009), y c) "Promoción del patrimonio histórico-cultural y desarrollo comunitario en pobladores mapuche y criollos de la provincia de Neuquén" (2008-2010). Todos ellos radicados en la Secretaría de Políticas Universitarias (SPU) del Ministerio de Educación de la Nación. 
En primer lugar, respecto del trabajo en la región de Norpatagonia, queremos destacar que constituyen un valioso antecedente las investigaciones realizadas, desde la década de 1980, por dos de los directores del programa: el Dr. Juan Carlos Radovich y el Dr. Alejandro Balazote. El camino labrado por estas experiencias nos ha permitido desarrollar, desde inicios de la década de 2000, tareas investigativas y diversas vinculaciones con referentes y comunidades mapuches de Norpatagonia.

En segundo lugar, en el año 2012 se abrió otra línea de trabajo referente a pueblos indígenas ubicados en varias localidades de la RMBA, así como en el interior de la provincia de Buenos Aires. A partir de ella, hemos mantenido diferentes proyectos UBANEX con el objetivo de abordar la presencia indígena urbana, formas de organización etnopolítica, participación estatal y ejecución de demandas para garantizar la ampliación de derechos ciudadanos, culturales y territoriales. Entre estas actividades se encuentran las que realizamos conjuntamente con el Consejo Indígena de Almirante Brown y la comunidad mapuche Calfulafken de la ciudad de Carhué, provincia de Buenos Aires.

De manera resumida, podemos decir que a lo largo de más de una década hemos sido beneficiarios de fuentes de financiación constantes para llevar a cabo un trabajo de extensión universitaria, ${ }^{11}$ lo que nos ha permitido contribuir a generar —colaborativamente con nuestros interlocutores- una multiplicidad de materiales audiovisuales e impresos ${ }^{12}$ que buscan desmitificar y refutar las imágenes que ubican a las poblaciones indígenas solamente como parte de la vida rural y que terminan por invisibilizar su presencia urbana.

Los Proyectos de Desarrollo Tecnológico y Social (PDTS) del CIN y el CONICET han sido otra fuente de recursos al interior del programa. Los mismos fueron una iniciativa orientada a financiar propuestas surgidas desde el ámbito universitario para definir estrategias y abordar problemas que demandara la comunidad en línea con el desarrollo sustentable del país, en pos de generar y aplicar conocimientos y soluciones.

Los PDTS contemplan la preocupación respecto de que los criterios de evaluación del personal científico y tecnológico, que se empezaron a aplicar, buscaban establecer una ponderación más equilibrada entre la ciencia básica y la ciencia aplicada, con el objetivo además de incentivar que las investigaciones se convirtieran en desarrollos concretos, prototipos o productos (Petz et al., 2016). Con este fin, en 2012 se conformó el Banco Nacional de Proyectos de Investigación y Desarrollo Tecnológico. Este agrupa los proyectos PDTS y es resultado del Documento I (2012), que refiere a la redefinición de los criterios de evaluación del personal científico y tecnológico.

En el año 2014 nos postulamos a dos ideas proyecto, y cabe destacar que uno de los requisitos fue su carácter interuniversitario. La múltiple adscripción institucional de las y los

11) El primer UBANEX fue obtenido en el año 2012. En total hemos llevado adelante ocho proyectos de los cuales los últimos dos son de tipo consolidado, es decir que su duración es de dos años. A continuación mencionaremos los títulos de los últimos: "Del territorio a la ciudad: movimientos indígenas, políticas públicas y acceso a los derechos en los ámbitos urbanos" (2016-2017); "Indígenas en la ciudad: articulación y fortalecimiento de espacios etnopolíticos en el Área Metropolitana de Buenos Aires" (2017-2018); "Indígenas en la ciudad: articulación y fortalecimiento de espacios etnopolíticos en el Área Metropolitana de Buenos Aires" (2018-2019); y para ver el título de la última convocatoria ver nota número 12.

12) Entre los materiales impresos podemos destacar dos folletos. El primero de ellos, "Los pueblos indígenas en las ciudades. Una realidad desconocida que despierta múltiples prejuicios” (2015); y el segundo, “¡Qué va a ser indígena si es mi vecino!. Indígenas en la ciudad: visibilizando una realidad desconocida y negada" (2016). 
miembros del equipo permitió saldar dicho requisito y desde 2015 fuimos beneficiarios de un PDTS radicado en la RMBA, ${ }^{13}$ y otro en la región de Norpatagonia. ${ }^{14}$

La maduración académica y de extensión de las y los integrantes del equipo por transitar en el marco de proyectos de Voluntariado, UBANEX y PDTS-CIN CONICET, no solo permitió definir objetivos específicos — realizables en el corto plazo- durante los encuentros mensuales, sino que generó las condiciones de una formación alejada del opuesto academicista de la disciplina antropológica entre el campo de "lo académico" y de "la extensión" universitaria. En nuestro caso particular, la articulación de ambas prácticas se fundió y se constituyó como un insumo del desarrollo profesional como antropólogos y antropólogas. Esto implicó también naturalizar metodologías de trabajo fuertemente vinculadas a las demandas indígenas, en clara articulación con funcionarios estatales de las diversas localidades de las provincias donde trabajamos. La presentación de los proyectos y sus requisitos definieron un interlocutor particular: "el demandante". O, en otras palabras, entre los formularios solicitados para cumplir con la presentación administrativa se debía adjuntar una carta de compromiso donde se detallara el consentimiento entre el equipo de investigación y la población indígena, así como los objetivos, resultados y actividades a desarrollar durante el proyecto.

Finalmente, antes de pasar a describir los casos etnográficos y los diversos formatos de vinculación etnográfica que llevamos adelante junto con las poblaciones indígenas, deseamos hacer una breve descripción de nuestra primera experiencia en torno a la curricularización de la extensión.

En 2010 la UBA creó el Programa de Prácticas Sociales Educativas y estableció que "son espacios curriculares obligatorios de enseñanza y aprendizaje cuyo desarrollo permite la articulación de contenidos curriculares con necesidades y demandas de la comunidad" (Resolución CS 3653/11: Art. 1). Esta modalidad sería optativa para aquellos estudiantes que ingresaron antes del año 2017 y obligatoria, gracias a la Resolución CS 172/14, para quienes lo hayan hecho posteriormente a ese año. En el caso de la FFyL, la curricularización de la extensión inició tempranamente en el marco de la Resolución CS 3653/11, y a partir de un importante proceso de acumulación de experiencias muy innovadoras en extensión universitaria que toman forma física en el año 2008 con la creación del Centro de Innovación y Desarrollo para la Acción Comunitaria (CIDAC) en el barrio de Barracas. El CIDAC se constituyó como una sede más de la FFyL, en donde se llevó adelante un programa de territorialización de la universidad en el barrio. ${ }^{15}$

Fue en el segundo cuatrimestre del año 2019 cuando realizamos nuestra primera experiencia de curricularización y extensión a través del dictado del Seminario de Vinculación y

13) Proyecto PDTS-CIN titulado "Del Territorio Rural a la Ciudad: características socioculturales, trayectorias de la migración y políticas públicas en relación a los pueblos indígenas en ámbitos urbanos”. IP 262 Director: Dr. Balazote, Alejandro. Universidad Nacional de Luján - Universidad de Avellaneda.

14) Proyecto PDTS-CIN titulado "Poblaciones Mapuche de la Cuenca del Nahuel Huapi: hacia el reconocimiento identitario y sus derechos socioeconómicos y culturales”. IP 252 Director: Dr. Valverde, Sebastián - Universidad de Buenos Aires - Universidad del Comahue.

15) En 2008 las autoridades de la FFyL, con la participación de los distintos claustros, convocaron la construcción de una propuesta institucional que habilitara a la Universidad y a los actores universitarios interesados (estudiantes, docentes, no docentes, investigadores y graduados) a desarrollar nuevas propuestas de prácticas universitarias que lograran situarse en las problemáticas de desigualdad presentes localmente en los territorios de la zona sur de la CABA (Cervera Novo, 2018). 
Prácticas Socioeducativas Territorializadas "Pueblos Indígenas, organizaciones etnopolíticas en contextos de Conflictividad" en el CIDAC. ${ }^{16}$ Este espacio institucional se constituyó como instancia de intervención concreta y específica vinculada al mejoramiento de diferentes problemáticas sociales, educativas y culturales, e implicó redefinir la tarea universitaria. Es decir que no se partió del conocimiento creado desde los paradigmas instituidos e institucionalizados académicamente sino desde los problemas científicos surgidos de las necesidades sociales existentes (Tommasino y Rodríguez, 2010; Trinchero y Petz, 2013). El Seminario fue clave a la hora de pensar la formación de grado, la extensión y la práctica docente como tareas articuladas y vinculadas a la formación académica de los y las integrantes del equipo.

Por último, en cuanto a los tres casos que desarrollaremos a continuación nos interesa aclarar que la noción de etnicidad ${ }^{17}$ que utilizaremos responde a que consideramos el proceso político y de formación de los dirigentes indígenas a partir del impacto que posee la militancia barrial en las trayectorias que atañen tanto a su formación y toma de conciencia étnica como a las modalidades de negociación y reclamo (Engelman et al., 2018). De esta forma, las poblaciones étnicas han logrado generar espacios de interacción y relacionamiento que les permiten disputar un poder en tanto organizaciones etnopolíticas (Castilla, Varisco y Valverde, 2018).

\section{Región Metropolitana de Buenos Aires: el y la antropóloga como técnico/a}

En párrafos atrás mencionamos que en 2012 comenzó (al interior del Programa de Etnicidades de la FFyL-UBA) la línea de trabajo junto con nucleamientos y familias indígenas en el contexto urbano. Aunque institucionalmente ello fue así, los primeros viajes al terreno los podemos situar durante los últimos meses del año 2008. El interés por la temática, al menos en el sur de la RMBA, surgió gracias al impacto positivo que tuvo la exposición de un banner - pegado en la vidiriera de un local- en una Unidad Básica cercana a la estación de Longchamps del tren General Rocal. En el cartel se difundía una actividad organizada por la "Coordinación de Pueblos Originarios de Almirante Brown" (en adelante CPOAB), dependencia que se enmarcaba en la Subsecretaría de Derechos Humanos e lgualdad de Oportunidades del municipio de Almirante Brown. El evento "Último día de Libertad de los Pueblos Originarios" invitaba a los vecinos y vecinas a participar de bailes tradicionales, consumo de comidas típicas y artesanía indígena, etc., en el parque de la estación de trenes de la localidad de Rafael Calzada.

A simple vista el cartel, por un lado, indicaba la existencia de un espacio municipal en el que participaban familias indígenas, y por otro, daba cuenta de la presencia y organización etnopolítica en la periferia de la RMBA (Engelman, 2017). Este escenario, al tiempo que sembró un conjunto de interrogantes, abrió el canal para que, durante los primeros meses del

16) Para aprobar la asignatura, las y los estudiantes elaboraron un video colectivo donde se difunde un conjunto de datos acerca de la presencia indígena en la ciudad con imágenes de una charla que se hizo en el CIDAC integrada por referentes indígenas y la Dra. Irène Belier de la Escuela de Altos Estudios de París como invitada. El video titulado "Siempre presentes. Indígenas en Buenos Aires" está disponible en: https://www.youtube.com/ watch?v=wj0YH3UP5FQ

17) Las investigaciones aquí mencionadas profundizan una línea de trabajo que entiende a la etnicidad como la expresión o acción de la identidad étnica (Bartolomé, 1997) y resalta su carácter dinámico, conflictivo y material (Bari, 2002). 
año 2009 — junto a dos compañeras del grado—, fuéramos designados por el coordinador del área indígena como parte de su "equipo técnico". Efectuado ese primer contacto, y de forma muy discontinua, concurrimos a las diferentes comunidades ubicadas en barrios periféricos de la zona ${ }^{18}$ con el objetivo de contribuir a la elaboración de un diagnóstico general sobre la cantidad de habitantes, la composición familiar, las condiciones de vida y el conjunto de demandas respecto del territorio y de la identidad. Los datos surgidos definieron un conjunto de ejes que, posteriormente, sistematizamos a partir de la realización de una propuesta metodología y teórica inicial, en línea con la solicitud del coordinador de la CPOAB. En simples palabras, el funcionario indígena nos demandó formar parte de un equipo técnico con el objetivo de asistirlo en la elaboración escrita de un proyecto. Esto implicó definir objetivos, realizar una fundamentación, una metodología, y confeccionar un presupuesto para llevar a cabo un "diagnóstico participativo" de los nucleamientos y familias indígenas ubicados en Almirante Brown como parte del Programa de Acompañamiento en Comunidades Indígenas (PACl) de la Ley 26.160. ${ }^{19}$

El trabajo etnográfico, así como los interrogantes y las temáticas a analizar durante la construcción del problema de investigación, coinciden con lo que Rita Segato define mediante la noción de "antropología por demanda" (2013). ${ }^{20}$ Aunque debemos destacar que, también, esa demanda tuvo un carácter específico. Nos referimos a la función técnico-administrativa que tuvimos a la hora de completar el formulario del proyecto PACl. Este "acceso al campo", como el de la mayoría de los y las antropólogas, estuvo reglado por múltiples intercambios, y recién hoy en día hemos tomado conciencia acerca del rol estatal que representamos en un comienzo.

Quienes realizamos trabajo en terreno con los protagonistas de nuestras investigaciones estamos advertidos de que nuestras intervenciones en esos espacios pueden afectar la vida cotidiana y los derechos de esas personas (Zenobi, 2019, p. 54). De esta manera, la etnografía involucra diversos problemas que se fundamentan en la convivencia y la participación del antropólogo en los entramados sociales de una diversidad de sujetos situados entre los diferentes contextos que transitamos a lo largo de las investigaciones. Ahora bien, si el trabajo con poblaciones indígenas en la RMBA partió de una demanda, podemos decir que continuó y se alimentó de la definición de una serie de obligaciones mutuas. Ese primer campo de relaciones finalizó con la presentación, en el año 2011, de la tesis de Licenciatura "Formas de organización social y liderazgo en comunidades indígenas urbanas: estrategias de acceso al poder, construcción y mantenimiento en un caso de titulación y lucha por tierras comunitarias. Comunidad Tupí Guaraní Cacique Hipólito Yumbay" (Engelman, 2011). En dicho

18) Durante esos meses visitamos las siguientes comunidades/nucleamientos: a) "Cacique Hipólito Yumbay" del pueblo tupí-guaraní; b) "Migtagan" del pueblo toba (qom); c) "Nogoyin Ni Nala" del pueblo mocoit; d) "Cacique Catán" del pueblo mocoit; e) "Cuimbaetoro" del pueblo ava-guaraní; f) "Guaguaji Jall'pa” del pueblo kolla; y f) "Juan Kalfulkurá” del pueblo mapuche.

19) La Ley 26.160 de Emergencia Territorial Indígena —sancionada en 2006 y prorrogada en 2009, 2013 y 2017 - resulta de vital importancia para las comunidades indígenas de la Argentina, ya que a partir de ella es posible frenar los desalojos y avanzar en el reconocimiento de los territorios tradicionales, en tanto funciona como prueba documental en pos de obtener el reconocimiento dominial.

20) Segato entiende que la "antropología por demanda" es un proyecto alternativo que expresa la disponibilidad de la antropología para ser interpelada por comunidades y pueblos que le colocan su "demanda" y permiten, de esa forma, que su "ciencia" obtenga un lugar y una razón en el camino del presente (Segato, 2013, p. 11). 
trabajo se enfatizó en el proceso migratorio y en las modalidades que adquiere el "liderazgo" indígena en contextos urbanos. Como etapa de reflexión primaria disparó un conjunto de interrogantes sobre la organización etnopolítica en el sur de la RMBA, lo que supuso considerar otras experiencias de organización comunitaria local para comparar y comprender el lugar que la articulación estatal tiene en los procesos de visibilización, institucionalización y participación indígena en Almirante Brown.

Ese plan de investigación se inició durante el doctorado, y gracias al otorgamiento de una beca del CONICET. En lo que hace a esta etapa (2013-2018), el trabajo de extensión universitaria fue decisivo tanto en la labor etnográfica como de investigación y definición del campo a indagar. La realización de observación participante, las entrevistas dirigidas y el tejido vincular de una dirigencia organizada etnopolíticamente, más allá de Almirante Brown, se vieron dinamizados por las actividades extensionistas que durante esos años llevamos a cabo con el equipo. La realización de talleres, charlas, ceremonias, audiovisuales y diversos materiales de difusión en el marco del CLPI y el trabajo colaborativo con un sector de la dirigencia etnopolítica de la RMBA y del interior de la provincia de Buenos Aires - San Pedro—, ${ }^{21}$ nutrieron la reflexión y la investigación doctoral a partir de una mirada regional.

La extensión universitaria, en la medida en que abarcó el trabajo con más nucleamientos, amplió las demandas y el campo etnográfico se complejizó. Esto último no implicó mayores dificultades prácticas sino que requirió discutir y problematizar la metodología inicial como consecuencia del tipo de relación que se había afianzado. Cuando sumamos la labor extensionista a la investigación financiada por la beca doctoral CONICET pudimos identificar ciertas tensiones con relación a la demanda, sobre todo acerca de nuestro rol. En la primera etapa hablamos de la función técnica con la que habíamos sido identificados, pero en esta segunda ocasión nuestra presencia e intervención fueron vistas como un mecanismo - directo e indirecto- que, en parte, legitimaban la práctica etnopolítica de las y los dirigentes indígenas. Por ejemplo, a fin de evitarlo, empezamos a rotar la participación en charlas y talleres de los y las dirigentes a lo largo del año, procuramos mantener un diálogo fluido con todos y todas, y recurrimos a distribuir, lo más equitativamente posible, los materiales impresos - folletos y banners - en la medida en que estos tomaban su forma definitiva. Lo mismo pasaba a la hora de rotar el lugar en que cada una de las actividades se hacía, ya que la presencia del equipo universitario en los espacios comunitarios empezó a generar cierta disputa al interior del campo etnopolítico. Por cuestiones de agenda no podíamos concurrir a todas las comunidades, y ello derivó en que lo mejor fuera realizar las charlas y talleres en el ámbito de la Universidad, por un lado, y el trabajo etnográfico en las comunidades, por el otro.

Durante esos cinco años aproximadamente, y a medida que tomábamos conciencia del impacto que generábamos en el entramado etnopolítico, el trabajo de extensión universitaria buscó implementarse mediante una distribución equitativa de recursos y de nuestras presencias en el terreno. Más allá de esta iniciativa, la cual fue pulida con el correr del

21) El equipo de investigación compartió talleres, charlas, presentaciones y ceremonias con la comunidad Lma lacia Qom de la localidad de San Pedro, provincia de Buenos Aires. Este trabajo en conjunto y en colaboración impactó de forma positiva en términos de difusión y visibilización de la presencia indígena respecto del Estado local y provincial. Para ver un trabajo en profundidad se puede consultar Míguez Palacio (2016). 
tiempo, cabe destacar que atravesamos igualmente un sinfín de conflictos, disrupciones y malos entendidos. Seguramente ello se debió a la complejización de vínculos y obligaciones y a la confianza que ganamos a lo largo de los años. Esto permitió ver las expectativas y los intereses específicos del grupo de dirigentes con quienes emprendimos la labor etnográfica. Ese acercamiento puso en cuestión la tajante división entre lo absolutamente público (por ejemplo, las demandas indígenas en los ámbitos locales) y lo absolutamente privado (por ejemplo, nuestra vida personal, así como los montos de recursos disponibles de los proyectos de extensión). Entendimos que la superposición de ambas esferas era un ingrediente que se sumaba tanto a la práctica como a la reflexión de nuestra tarea como antropólogos y antropólogas. De igual modo, aquello que resultaba conflictivo pasó a formar parte de las dinámicas y los formatos vinculares entre las y los miembros del equipo de investigación y las y los dirigentes indígenas. En otras palabras, aquel rol utópico de la antropología caracterizado por la neutralidad y la objetividad fue tensionado a lo largo de nuestra formación al interior de un equipo de investigación que dinamizó labores académicas y de extensión universitaria. Por un lado, dicha etapa finalizaría en el año 2017 con la defensa de la tesis doctoral "Identidad étnica y práctica política en el sur del conurbano bonaerense" (Engelman, 2017) y, por el otro, continuaría con la obtención de una beca posdoctoral CONICET entre los años 2018 y 2020.

Otro punto central en el proceso de maduración de la formación académica en extensión fue el proyecto PDTS-CIN 262. ${ }^{22}$ Como mencionamos líneas atrás, uno de los requisitos para la presentación fue articular dos o varias instituciones universitarias como sujetos ejecutantes. Gracias a la multiplicidad de adscripciones institucionales que posee el equipo ${ }^{23}$ nos vinculamos con la Universidad Nacional de Avellaneda (UNDAV), más específicamente con su Secretaría de Extensión Universitaria. En 2017 iniciamos un trabajo en el que se articuló docencia, investigación y extensión, pero esta vez desde un lugar más novedoso, es decir, a partir de relaciones interuniversitarias. La fuente de financiación reposicionó el trabajo, amplió la participación de población indígena y de estudiantes y graduados, con el objetivo de contribuir a revertir el proceso de estigmatización e invisibilización indígena en ámbitos urbanos de la RMBA - y zonas aledañas-. Con este fin, al tiempo que continuamos con la investigación con relación a la temática, se elaboraron diferentes materiales para uso y difusión por parte de las organizaciones indígenas y de organismos estatales y no estatales.

Como objetivos complementarios, en primer lugar se buscó favorecer el fortalecimiento de la identidad comunitaria y de los diferentes grupos de los pueblos originarios Qom, Tupi Guaraní, Kolla, Mocovi, Mapuche y otros que han atravesado diferentes procesos migratorios. En segundo lugar, se procuró potenciar el acceso de estas poblaciones indígenas urbanas a diferentes derechos y prestaciones sociales que la población indígena tuvo como beneficiaria en los últimos años - de manera directa e indirecta- y en cuanto a la concreción de las cuales en la actualidad manifiesta diversas dificultades.

22) Ver en nota al pie número 12.

23) Además de formar parte del equipo de investigación del Instituto de Ciencias Antropológicas y de materias de la carrera de Antropología Social en FFyL-UBA, algunos de nosotros y nosotras nos desempeñamos como docentes en la Universidad Nacional de Luján (UNLu). 
Entre los productos finales queremos destacar la edición de un corto documental que tuvo por motivo contribuir a la difusión y visibilización de demandas, presencias y formas de organización etnopolítica en la periferia urbana. ${ }^{24}$ Se buscó generar materiales de fácil replicación a través de plataformas virtuales y así subsanar la carencia de información disponible acerca de estos grupos, sus características socioculturales, dinámicas migratorias, aspectos socioeconómicos, laborales y políticos. Este tipo de insumo, junto a los folletos, se tornó una herramienta que las y los dirigentes indígenas utilizan en su trabajo cotidiano con escuelas, municipios, charlas locales, etcétera.

En este apartado hemos destacado tres aspectos esenciales que surgieron a partir de la práctica extensionista. Primero, hicimos foco sobre el rol estatal que poseemos como antropólogos y antropólogas en el marco de las demandas de las poblaciones con que trabajamos. Segundo, resaltamos que la ampliación de espacios etnográficos impulsó la reflexión acerca de la metodología de trabajo al interior del equipo. Y, finalmente, las diversas líneas de financiación implicaron llevar adelante de modo articulado un trabajo académico, docente y de extensión entre diversas universidades nacionales. A continuación pasaremos a describir el trabajo que el equipo realiza desde el año 2018 con la comunidad mapuche Calfulafken de la ciudad de Carhué, provincia de Buenos Aires.

\section{Comunidad Calfulafken, Carhué}

Esta comunidad se encuentra en la localidad de Carhué ${ }^{25}$ provincia de Buenos Aires, cercana a la conocida Zanja de Alsina del siglo $\mathrm{XIX}^{26}$ (Nagy, 2013). Este nucleamiento está compuesto por alrededor de 35 integrantes que se autorreconocen y se adscriben como pertenecientes al pueblo mapuche. En 2018 se acercaron al equipo de trabajo ${ }^{27}$ con una necesidad específica: pedir apoyo para la tramitación de su personería jurídica para ser reconocidos ante el Estado nacional. ${ }^{28}$ De esta manera la primera vinculación con las múltiples familias de la comunidad supuso la interpelación desde una demanda específica y en clara vinculación con el trabajo académico y de extensión.

La población mapuche de Carhué expresa un proceso de revalorización de la identidad indígena, de sus reclamos y demandas. La organización de la comunidad y la intervención del equipo de investigación son parte de un escenario caracterizado por la emergencia étnica (Bengoa, 2009). Es en este proceso que las poblaciones indígenas deben demostrar

24) El corto Pueblos Originarios. Desafíos es un video realizado entre la UNDAV, la UNLu y la UBA a partir de de múltiples entrevistas con referentes de distintas comunidades indígenas argentinas. La producción da testimonio de la lucha por el territorio, la identidad, la cultura de los pueblos originarios y el desafío de la universidad en torno a su visibilización. Disponible en UDAVTv: https://www.youtube.com/watch?v=W-uDuBQYjhE

25) Carhué se encuentra ubicada a orillas del lago Epecuén y cerca del arroyo Pigüé, al oeste de la provincia de Buenos Aires, partido de Adolfo Alsina, Argentina. A unos 500 kilómetros de Capital Federal y a 200 kilómetros de Bahía Blanca.

26) Estrategia planeada por el ministro de Guerra Adolfo Alsina para avanzar sobre los territorios indígenas, en lo que es la actual región de Buenos Aires, mediante el emplazamiento de comandancias militares y fortines.

27) UBANEX "Indígenas en la ciudad: visibilización y organización etnopolítica en el marco de las transformaciones recientes", Programa de subsidios de extensión universitaria UBANEX - $11^{\circ}$ convocatoria "Consolidando las prácticas sociales educativas".

28) Conformarse como comunidad implica la tramitación de la personería jurídica. 
derechos sobre territorios de los que fueron expulsadas, donde la memoria resulta central (Valverde, 2011). Por lo tanto, en este camino se necesita el reconocimiento jurídico así como generar espacios y redes para lograr mayor visibilidad y fortalecimiento del reclamo.

En este sentido, nos parece importante remarcar que el sistema burocrático estatal exige ciertos requisitos a la hora de iniciar la tramitación de personería jurídica ante el Instituto Nacional de Asuntos Indígenas (INAI). Dicho reconocimiento es importante para poder realizar pedidos y negociar con los entes estatales (Weiss, Engelman y Valverde, 2013; Engelman et al., 2018). En cuanto al caso de Calfulafken, se optó por iniciar el trámite ante la provincia de Buenos Aires y no ante el organismo nacional. Ello fue así porque el INAl en los últimos años demora más tiempo en extender los reconocimientos hacia las comunidades. $Y$ hay que aclarar que, según el Reglamento de funcionamiento del Registro Provincial de Comunidades Indígenas (REPROCI) ${ }^{29}$ y su respectivo instructivo, los principales puntos que se solicitan/recomiendan para la tramitación de la personería jurídica son: explicitación del motivo del pedido de reconocimiento, nombre de la comunidad, miembros de la comunidad (censo) y reglamento comunal (formas de elección y remoción de autoridades, duración de mandatos, etc.), reseña histórica del pueblo de pertenencia, entre otros. Por último, el trámite necesita la certificación de funcionarios del organismo interviniente que van a visitar a la comunidad y verificar lo detallado en los papeles. ${ }^{30}$

A simple vista, los requerimientos, muchas veces, son instancias administrativas complejas y de difícil realización. La mayoría de las comunidades debe solicitar el apoyo de antropólogos, abogados o también optar por el asesoramiento de otras comunidades indígenas que ya los hayan atravesado satisfactoriamente. Este fue el caso de la comunidad Calfulafken. Es importante aclarar que el método de trabajo se estableció de manera conjunta. Es decir que se realizaron entrevistas a los integrantes de mayor edad para reconstruir la historia comunal, se trabajó en el archivo zonal para buscar registros - mapas, fotos, expedientes- que apoyaran la presencia de antiguos asentamientos indígenas en la región y se reconocieran los espacios donde se asentaron las primeras familias. A su vez, se buscó orientar aquellos interrogantes que surgieron de los puntos solicitados en el instructivo de la personería jurídica para, luego, realizar y presentar ante el organismo estatal la documentación pertinente. A partir de los primeros contactos con el equipo de investigación, varios integrantes de la comunidad comenzaron a participar activamente en las charlas y actividades que realizábamos en universidades y escuelas con el objetivo de visibilizar sus demandas y compartir el proceso de organización que atravesaban. ${ }^{31}$

Muchos de estos requisitos suelen convertirse en obstáculos porque se solicita información de difícil, o imposible, reconstrucción debido a los sucesivos despojos y violencia a la que fueron expuestas estas comunidades. Además, muchas veces se convierte en un trámite para demostrar la autenticidad indígena desde una visión idealizada y ahistórica (Trinchero

29) Funciona en el CPAI a partir de un convenio con el INAI. Su función es tramitar y otorgar la personería jurídica a las comunidades indígenas de la provincia que lo soliciten.

30) Guía para la inscripción en el Registro Provincial de Comunidades Indígenas y Reglamento de funcionamiento del Registro Provincial de Comunidades Indígenas (REPROCI). Disponibles en https://www.gba.gob.ar/derechoshumanos/consejos_provinciales

31) Uno de los testimonios que incluye en el corto documental mencionado en la nota al pie número 2 pertenece a un integrante de la comunidad Calfulafken. 
y Valverde, 2014). Pero a la vez es un proceso que puede posibilitar organización comunitaria y empoderamiento (Guiñazú, 2018). Por ejemplo, las familias y miembros de la comunidad Calfulafken cohesionaron sus esfuerzos durante la realización de los trámites de la personería jurídica al tiempo que comenzaron a vincularse con otras comunidades, universidades y distintas instituciones de la zona. Cabe resaltar que en este proceso de censar a las familias indígenas algunos de los habitantes, a partir del contacto con las y los dirigentes, empezaron a participar y/o a contar de forma más abierta sus orígenes indígenas.

Con relación a este punto, el primer paso de la comunidad fue la vinculación con comunidades de zonas cercanas, que ya habían tramitado la personería jurídica y que se encontraban organizadas desde hacía varios años, como las comunidades mapuches de la ciudad de Bahía Blanca o de Los Toldos..$^{32}$ Este entramado de relaciones, que exceden lo local, lo podemos ver, por ejemplo, en la publicación de notas periodísticas que relatan la organización en común de diversas actividades, como la celebración del año nuevo mapuche en el lago Epecuén de Carhué, donde también participaron integrantes de Bahía Blanca (Cambio 2000 Online, 2017).

Dichas redes de relaciones abren nuevos espacios de participación, como el Consejo Indígena de la Provincia de Buenos Aires (CIBA) ${ }^{33}$ conformado por representantes de pueblos que habitan la provincia. Es así que este año el dirigente de Carhué participó por primera vez en la elección de las nuevas autoridades indígenas que se realizó en la ciudad de La Plata, provincia de Buenos Aires. Estos son espacios de alianzas y disputas donde entran en juego negociaciones e intereses. Además, estos ejemplos son una forma de pensar el lugar del Estado en los ámbitos locales y las prácticas populares (jurídicas y extrajurídicas) en continua conformación e interrelación (Milanich, 2009).

En cuanto al trabajo en extensión, en el año 2019 elaboramos de manera conjunta el folleto No entregar Carhué al huinca (Comunidad mapuche Kalfu Lafken, Varisco y Valverde, 2019), el cual contiene un conjunto de temas relevantes y elegidos para ser difundidos por la comunidad. Este ha sido distribuido a sus integrantes a distintas oficinas municipales del área de cultura, a la Biblioteca Popular Adolfo Alsina, al Museo Regional Dr. Adolfo Alsina y al Archivo Histórico dependiente del mismo. Los y las integrantes de Calfulafken también asistieron a diversas instancias de difusión de la zona, como por ejemplo la radio local de Carhué. Según la dirigencia indígena, el objetivo de asistir a estos canales de difusión "es para mostrarle a la gente que estamos avanzando y haciendo cosas, que no va a quedar todo en la nada", señala una dirigente de la comunidad Calfulafken (Comunicación personal, julio de 2019).

El testimonio citado da cuenta del trabajo etnopolítico local y refleja el uso e impacto particular de los materiales que se producen en el marco de la extensión universitaria. La importancia que se le da al folleto se puede vincular con lo que sostiene Barrera (2014) sobre la capacidad que tienen los documentos de ser espacios de construcción y validación del saber, así como de subjetividad y poder. En este sentido, vemos que la realización en

32) Comunidad mapuche Lof Kuripan-Kayuman de Bahía Blanca y Comunidad mapuche Tribu Ignacio Coliqueo de los Toldos.

33) Las normativas vigentes sobre el CIBA son el Decreto 3631/07 y la Resolución 158/06. Integra el Consejo Provincial de Asuntos Indígenas (CPAI), órgano de codecisión perteneciente a la Secretaría de Derechos Humanos de la Provincia de Buenos Aires. El CIBA se encuentra conformado por representantes de pueblos de la provincia de Buenos Aires y por dos representantes elegidos en asamblea de los pueblos mapuche-tehuelche, kolla, qom y guaraní. 
conjunto de materiales impresos, o la asistencia a las grabaciones audiovisuales de cierto sector de la dirigencia indígena, pueden incidir en los procesos de organización etnopolítica local. En otras palabras, muchas veces acompañamos procesos de legitimación de dirigentes indígenas, lo que puede provocar escenarios de mayor o menor conflictividad. Gran parte de ello ha sido reflexionado en los talleres colectivos que mensualmente lleva adelante el equipo de investigación y extensión. Se trata de destacar el impacto directo que nuestras presencias tienen no solo a través del trabajo etnográfico sino mediante la realización de materiales particulares.

Finalmente, cabe mencionar que la comunidad Calfulafken, a mediados de 2019, presentó los papeles ante el REPROCI y ya posee su número de expediente. Seguidamente, se comenzaron a plantear otras necesidades, como el pedido de tierras al gobierno de la provincia de Buenos Aires, establecer un centro cultural para realizar actividades y reuniones de la comunidad y la solicitud de arqueólogos que lleven adelante una prospección en la zona del lago Epecuén.

\section{La región del lago Nahuel Huapi en la zona cordillerana de Norpatagonia, el PDTS y el trabajo con el pueblo mapuche}

La línea de trabajo en Norpatagonia se lleva adelante en la zona norte del Parque Nacional Nahuel Huapi, en el departamento Los Lagos de la provincia de Neuquén, y también en la margen sur de esta área protegida, que corresponde al departamento Bariloche de la provincia de Río Negro (ya que el lago funciona como límite entre ambas provincias). Esto incluye la zona del parque nacional y, a la vez, los ejidos municipales Villa la Angostura y San Carlos de Bariloche - cabeceras de ambas jurisdicciones provinciales, respectivamente- La ciudad de San Carlos de Bariloche se sitúa en la orilla sur del lago Nahuel Huapi (ver Figura 1) y, de acuerdo con el último censo de población de 2010, cuenta con 112887 habitantes (diario Río Negro, 2013). Es la principal ciudad y centro turístico de esta región de Los Lagos. Esta zona limita con Chile y la Cordillera de los Andes obra de frontera jurídico-política entre ambos países.

En la costa norte del lago Nahuel Huapi, en la provincia del Neuquén, se asienta la localidad de Villa la Angostura, de menor densidad demográfica y más orientada a un turismo de elite, de alto poder adquisitivo. Esta ciudad creció como parte de la influencia que ejerció Bariloche en la zona y, en especial, a partir de la fundación del Parque Nacional Nahuel Huapi. De hecho, esta localidad fue una de las siete "villas turísticas" fundadas por esta institución (en la década de 1930). Villa la Angostura comenzó a crecer aceleradamente en las últimas dos décadas. En 1991 poseía 3056 habitantes; en 2001, 7325; y en 2010, 11087 habitantes (conforme a cifras provisorias del censo 2010; diario La Mañana del Neuquén, 2010). 
Figura 1: Mapa de la provincia de Río Negro (sector central y occidental, zona del Parque Nacional Nahuel Huapi)

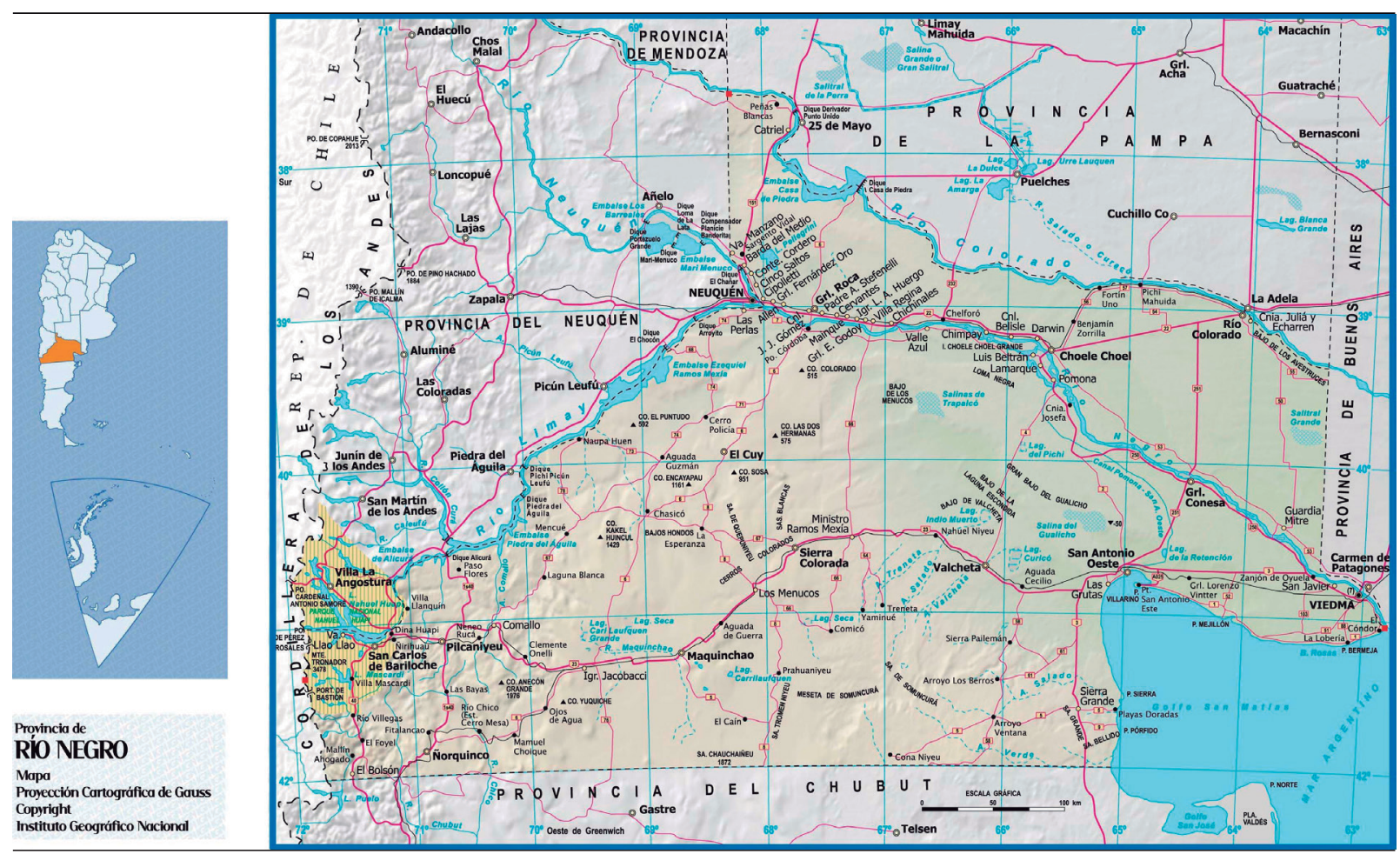

Fuente: Instituto Geográfico Nacional

A partir de la expansión turística e inmobiliaria —y la acelerada construcción de residencias de gran valor monetario y el aumento de la población — se ha incrementado la presión sobre los territorios, lo que genera agudos conflictos entre diferentes sectores, especialmente con la comunidad mapuche local Paichil Antriao.

En los últimos años, desde el ámbito nacional y desde las provincias de Neuquén y Río Negro, así como desde el Municipio de San Carlos de Bariloche, junto con otras instituciones relacionadas (Parques Nacionales, etc.) se ha efectuado el reconocimiento de la preexistencia del pueblo mapuche y de sus derechos como grupo originario. ${ }^{34}$ No obstante, la presencia de discursos estigmatizantes (o abiertamente racistas) no solo es replicada en la actualidad sino que se ha incrementado en la medida en que organizaciones y comunidades disputan sus territorios ancestrales, crecientemente, con diversos agentes privados. En contraste con las demás instituciones, el reconocimiento del Municipio de Villa la Angostura a la comunidad mapuche Paichil Antriao es más difuso y contradictorio, acorde con los fuertes intereses inmobiliarios que entran en conflicto con esta comunidad.

34) No así el Municipio de Villa la Angostura, que aún dista de su formalización, si bien en los últimos años se han establecido mayores canales de diálogo con la comunidad Paichil Antriao. 
Cabe destacar que desde 2003 hemos desarrollado diferentes trabajos que podemos caracterizar como "horizontales" y/o "participativos" entre dirigentes e integrantes de la mencionada comunidad con diferentes organizaciones de mapuches y pobladores. Los hemos realizado tanto con organismos públicos, como el INAI, y a partir de proyectos financiados por el Ministerio de Educación (por ejemplo, los proyectos de Voluntariado Universitario), aportes que se ven reflejados en múltiples resultados. ${ }^{35}$

EI PDTS que comenzamos a instrumentar en 2015 implica un trabajo articulado entre las instituciones del saber científico y académico, las organizaciones indígenas y diversos organismos locales, con el propósito de brindar soluciones a los problemas que afectan a los pueblos indígenas. Es instrumentado por la UBA, la Universidad Nacional del Comahue (UNCo), el CIN y el CONICET.

Orientadas también a lograr esas soluciones, participan, además de diferentes comunidades mapuches (Paichil Antriao, Quintriqueo, Quintupuray, Takul Cheuque, Wiritray), instituciones como la Biblioteca Pública Municipal Raúl Alfonsín, de Bariloche, y el Programa Radial de LRA30 Radio Nacional Bariloche Patagonia Camino y Tiempo. Luego, durante la implementación del proyecto, se sumaron la Defensoría del Pueblo (dependiente de la Municipalidad de San Carlos de Bariloche), la Secretaría de Derechos Humanos de la provincia de Río Negro y la Biblioteca Popular Osvaldo Bayer de Villa La Angostura.

Al inicio del proyecto nos proponíamos identificar y abordar las dificultades que poseen las comunidades y las organizaciones indígenas para acceder a los derechos establecidos en diversas legislaciones y en programas sociales que presentan impedimentos para su concreción, lo que genera que entre "lo dicho y el hecho" haya todavía grandes (a veces enormes) distancias. La propuesta era elaborar diversos materiales didácticos (folletos, carteles, publicaciones de difusión, etc.) con el objetivo de concientizar al conjunto de la población acerca de los mensajes estigmatizantes y racistas que aún perduran y responder a ideas muy difundidas, como la que propugna la supuesta contradicción entre documentos y relatos orales sobre la existencia de indígenas en la zona. Así, destacábamos, a partir del conocimiento académico, las múltiples falacias que tales discursos poseen. Paralelamente, un aspecto central de la propuesta es la participación de los propios beneficiarios en la generación de esos resultados mediante trabajo conjunto y combinado con los profesionales del

35) En 2003, a partir del trabajo de investigación que desarrollamos en Norpatagonia, iniciamos una tarea conjunta de transferencia y apoyo a los pobladores mapuches de la localidad de Villa La Angostura (departamento Los Lagos, provincia del Neuquén). Efectuamos un estudio, a pedido del INAI, basado en la recopilación de historias de vida y fuentes documentales de los pobladores Paichil Antriao y Quintriqueo, que reclamaban su reconocimiento como comunidad mapuche. El proyecto finalizó con la publicación de un libro (Historia de las familias Mapuche Lof Paichil Antriao y Lof Quintriqueo de la Costa Norte del Nahuel Huapi) compilado por la Biblioteca Popular, con diversos artículos que reflexionan acerca de la problemática mapuche y recopilan las historias de vida de los pobladores. Este estudio fue clave para que obtuvieran la personería como comunidades ante el INAI, lo que se concretó en 2007. Entre 2006 y 2009, trabajamos en diferentes proyectos de Voluntariado Universitario centrados en la recuperación de los testimonios de los pobladores de la zona de Villa Traful y áreas aledañas que concluyeron en la publicacion Relatos Patagónicos. Historias familiares en la construcción del espacio social en Villa Traful, de Sebastián Valverde, Analía García y Lara Bersten (2008). En la convocatoria 2010 del proyecto de Voluntariado Universitario efectuamos un análisis entre comunidades mapuches de la provincia de Río Negro. El resultado fue la obra Volver al Territorio. Memorias mapuches en el Parque Nacional Nahuel Huapí, de Sebastián Valverde, Florencia Trentini, Alejandra Pérez y Gerardo Ghioldi (este último de la Biblioteca Popular Osvaldo Bayer), editado por la FFyL-UBA (Valverde, Trentini, Pérez y Ghioldi, 2013). 
ámbito universitario. En efecto, este PDTS recupera la experiencia y los diversos contactos que hemos desarrollado desde hace años con diversas comunidades mapuches y los denominados "pobladores" de la región del Parque Nacional Nahuel Huapi. ${ }^{36}$

Ahora bien, este era el planteo que formulábamos al inicio del proyecto, en 2015. Una nueva realidad, completamente diferente, inició en el año 2017. Mientras desarrollamos este proyecto, se intensificó un escenario de un creciente nivel de conflictividad con las comunidades mapuches, con una inédita presencia del tema indígena $-\mathrm{y}$ en particular de este pueblo- en los medios de comunicación y en la opinión pública. La desaparición (y luego confirmación de muerte) del militante Santiago Maldonado en el contexto de la represión a la comunidad Pu Lof Cushamen de la provincia del Chubut y los hechos que sucedieron en el Lago Mascardi en noviembre de 2017 (en la zona donde se desarrolla nuestra investigación) que tuvieron como trágico saldo la muerte del joven mapuche Rafael Nahuel (a partir del accionar de las fuerzas de seguridad), marcan la realidad de esos meses. Sin dudas, esto está estrechamente ligado a las políticas neoliberales implementadas por la presidencia de gobierno de Mauricio Macri (2015-2019) y las diversas transformaciones instrumentadas por entonces. Una de ellas fue la modificación, mediante el Decreto 820/2016, de la Ley 26.737, de Protección al Dominio Nacional sobre la Propiedad, Posesión o Tenencia de las Tierras Rurales, que diluye los controles y facilita la extranjerización de la tierra (que estaba limitada por la ley sancionada por el anterior gobierno en 2011) y dificulta aún más el acceso de las familias indígenas a este recurso, al igual que para los pequeños productores rurales. Las disputas que involucran al pueblo mapuche también se vienen dando con otros pueblos indígenas a lo largo del país, principalmente en las provincias de Formosa, Tucumán, Misiones, Santiago del Estero, Salta y Jujuy (Aranda, 2017). ${ }^{37}$

Como vemos, estos sucesos representan un cambio muy profundo en relación con la problemática que afecta al pueblo mapuche. También es necesario destacar cómo esto incidió en la interrelación con diferentes organismos, además de las repercusiones nacionales e internacionales de estos graves acontecimientos. Como consecuencia, se produjeron grandes cambios y redefiniciones en el desarrollo del trabajo. Uno de ellos consistió en centrarnos en la elaboración de una publicación de difusión cuyo título es El prejuicio hacia el pueblo Mapuche como supuestamente "chileno": una invención sumamente interesada y largamente refutada (Maragliano et al., 2017), cuyo objetivo fue desmentir prejuicios respecto de esta idea falaz y largamente extendida que pretende negar los derechos ancestrales del pueblo mapuche.

36) Esta denominación englobadora de "pobladores" fue definida desde las políticas estatales e internalizada por los propios sujetos como forma de designarse a sí mismos y a otros. Se refiere a que son oriundos del lugar. También remite a una idea de que son pequeños productores. Esta categoría representa un universo sumamente heterogéneo que, en algunos casos, posee una raíz cultural común con los indígenas (no así en otros, que son de origen criollo o, en menor medida, europeo, pero al ser de escasos recursos quedan incluidos en este grupo) (Valverde, García y Bersten, 2008).

37) Durante 2017 se fueron multiplicando situaciones comparables. Tal es el caso de una comunidad indígena del pueblo guaraní en la provincia de Salta (en el noroeste del país) que denunció el accionar violento de un empresario para apropiarse del territorio indígena y que reclamó se cumplan sus derechos ancestrales. Pero la justicia y las autoridades - en evidente complicidad con el empresario- no dieron lugar a ninguna de las denuncias. En cambio, la respuesta fue la represión a la comunidad. De hecho, un dirigente comunitario estuvo preso doce días acusado de presuntas "amenazas" por parte de un empresario del agronegocio (Aranda, 2017). 
Otro de los resultados que hemos logrado a lo largo de este proyecto consiste en la confección de mapeos participativos, desarrollados en forma conjunta entre los integrantes de las comunidades mapuches y los profesionales que integramos el PDTS. Uno de los trabajos que hemos elaborado es el registro y la sistematización de los diferentes usos históricos por parte de la comunidad Lof Quintupuray en la costa norte del lago Correntoso, a unos 30 kilómetros de la localidad de Villa la Angostura, a partir de la memoria y los relatos de los pobladores (en especial, los denominados kuifikeche, aquellos de mayor edad). En este tipo de resultados participativos, de acuerdo con Tipula (2008), es posible recopilar las percepciones de los pobladores y sistematizar elementos materiales, inmateriales y simbólicos del paisaje. Esto es clave al momento de interpretar y redefinir el territorio, en particular cuando se aborda esta temática en el contexto de un pueblo originario.

El accionar del proyecto en el territorio se basó en un trabajo conjunto con las organizaciones étnicas, lo que posibilitó la construcción de espacios de intercambio de conocimientos y saberes que ayudaron a visibilizar esas nuevas realidades profundamente dinámicas.

Por lo tanto, el desafío metodológico planteado en la implementación de esta metodología participativa de mapeo implica una concepción dinámica en la que "los elementos materiales, simbólicos y espirituales se consideran vinculados dialécticamente, de modo tal que no puede decirse que alguna de estas dimensiones pueda tener precedencia o mayor importancia que la otra" (Rodríguez de Anca, Villareal y Valdéz, 2013). De hecho, desarrollamos la experiencia de un trabajo elaborado en forma conjunta, donde somos autores tanto los académicos como los integrantes de esta comunidad.

Trabajamos en la recuperación de los recuerdos de los actuales miembros mayores (kuifikeche), quienes poseen los conocimientos del Lof Kintupuray. A la vez, se acudió a documentos como los expedientes de Parques Nacionales o diversas fuentes históricas. Como fruto de estas labores, se elaboró el "Informe histórico-antropológico del Lof Kintupuray" en forma conjunta entre dirigentes e integrantes de la comunidad y profesionales de las UBA, la UNCo, la UNLu y el CONICET en el marco del PDTS ya mencionado (Quintupuray et al., 2018). A partir de este trabajo, se puede observar la continuidad durante el desarrollo de estas actividades tradicionales propias del pueblo mapuche (por ejemplo, agricultura a pequeña escala y ganadería) y la relación con otras poblaciones mapuches y vecinos, al igual que la interacción con diversos organismos públicos a lo largo del tiempo.

Los encuentros con los pobladores mapuches concretaron trabajos sistemáticos de relevamientos territoriales desde perspectivas endógenas y de pertenencia cultural y posibilitaron analizar y poner en discusión (y también en tensión) cómo las normativas legales vigentes ambientales (Ley de Bosques y reglamentos forestales de la Administración de Parques Nacionales) resultan contradictorias con el actual derecho indígena.

A partir de la realización de este trabajo, y de la presentación ante la dirección de personerías jurídicas de la provincia de Neuquén, fue que el Lof. Kintupuray obtuvo su formalización por parte del Estado provincial.

Actualmente, realizamos una tarea comparable con la comunidad Lof Wiritray (27 kilómetros al sur de la ciudad de San Carlos de Bariloche, en la provincia de Río Negro), el que, considerando la situación planteada desde fines de marzo de 2020 (con la expansión del coronavirus como pandemia y con el consiguiente Aislamiento Social Preventivo y Obligatorio decretado a partir del 20 de marzo), lleva a replantear los plazos y labores y traerá 
como resultado un trabajo comparable al que efectuamos en el Lof Kintupuray. En efecto, la concreción del proyecto PDTS posibilitará publicar un trabajo que se encontraba avanzado, pero no concluido, a partir de otros proyectos de Voluntariado Universitario -elaborados en forma conjunta con la comunidad— titulado "Wiritray, algo que está surgiendo".

A esto se suma el resultado que hemos obtenido con el Lof Paichil Antriao, en el que demostramos que Paichil, que da origen a dicha comunidad, provenía a fines del siglo XIX de la región de Salinas Grandes (actual provincia de La Pampa), al huir de la campaña militar de fines del siglo XIX que avanzaba desde el este. Así es como José María Paichil se refugia en lo que hoy es Villa la Angostura (Collinao et al., 2019). Este trabajo fue presentado a la comunidad en diciembre 2019 y al público en marzo de 2020. En dicha instancia, se contó con la presencia de las autoridades del INAI además de referentes sociales y políticos locales y público.

\section{Consideraciones finales}

Como hemos analizado en los apartados anteriores, en la década de 1990 y, en especial, en los últimos años, se ha implementado una serie de experiencias que implican un trabajo que cuestiona la tradicional separación entre la investigación y la denominada "transferencia" y "extensión", en abierta critica al denominado "academicismo" o "cientificismo", tal como ha problematizado largamente Varsavsky (1969). Este camino alternativo conduce —además-a las diferentes articulaciones intersectoriales e interinstitucionales, ya que no es solo la academia la que está en condiciones de abordar las diferentes problemáticas. De allí la creciente presencia de la universidad en diferentes ámbitos territoriales, como describimos a partir de los casos del sur de la RMBA, el interior de la provincia de Buenos Aires y Norpatagonia.

Estas experiencias de trabajo permitieron definir que el objetivo no es buscar aquello que diferencia sino lo que se comparte para repensar lo étnico en el mundo contemporáneo y, así, estimular, más allá de su cosificación, formatos novedosos de relación y participación sociopolítica, económica y cultural de la diversidad en el marco de políticas públicas, la universidad y la multiplicidad de instituciones. Este contexto sociopolítico entendemos que colabora en cuanto a la producción de condiciones para el debate, es decir, a repensar las dimensiones constitutivas de los vínculos universidad-sociedad (Petz, 2015), lo que permite diseños institucionales novedosos que replican discusiones y prácticas universitarias en contextos alejados de las mismas. De esta manera, la labor profesional en extensión no solo ha influenciado en los formatos y en la formación de las nuevas generaciones de tesistas, becarios, becarias, investigadores e investigadoras, sino que ha canalizado el otorgamiento de múltiples subsidios que contribuyen tanto a reproducir como a replicar dicha práctica.

Esto permite pensar los problemas sociales no solo con vistas a efectuar un diagnóstico —como lo haría la ciencia "básica" o "pura- sino también para hallar soluciones, ya que conlleva la interdisciplinariedad y, a la vez, el trabajo intersectorial e interinstitucional. Como señalamos en otra oportunidad: "pensar el problema en los términos de su solución nos sitúa en la generación de una trama de articulaciones disciplinares, intersectoriales y comunitarias donde la universidad pierde la potestad del saber y reconoce la agencialidad epistémica de otros" (Trinchero y Petz, 2014, p.147).

Una vez asumido institucionalmente dicho desafío, los procesos de gestión comienzan a promover y estimular, por un lado, cruces interdisciplinarios desde la convicción episte- 
mológica que comprende a la realidad como estructurada pero, a la vez, como estructurante y en permanente contradicción. Por otro lado, también modalidades de construcción colectiva de conocimiento a partir de la convicción respecto de lo que hemos denominado "democratización epistemológica" (Petz, 2008). Esto se asienta en aquella tradición que reconoce a los sujetos populares no solo como sujetos de derecho a la educación sino también como productores de conocimiento legítimo. Se entiende así que la democratización epistemológica implica, necesariamente, crear condiciones para la participación de la mayoría de la población en los procesos de generación y validación de conocimiento teórico y técnico-metodológico (Petz, 2008).

Por todo ello, no investigamos o trabajamos "sobre" determinada población o grupo sino "con" ellos (Mato, 2014; Bartolomé, 2003) en forma articulada y mancomunada. Consideramos que esta tendencia está en sintonía con la categoría de "movilización del conocimiento" (Naidorf y Perrota, 2015), como hemos señalado. Además, la extensión universitaria, en la medida en que abarcó el trabajo con más nucleamientos, amplió las demandas y el campo etnográfico se complejizó. Esto último no implicó mayores dificultades prácticas sino que requirió discutir y problematizar la metodología inicial como consecuencia del tipo de relación que se había afianzado.

En definitiva, la participación en distintos proyectos (Voluntariado, UBANEX y PDTSCIN CONICET) nos permitió generar las condiciones de una formación alejada del opuesto academicista de la disciplina antropológica mediante la articulación de ambas prácticas con relación a las demandas indígenas. Por ello, la perspectiva que se viene construyendo supone redefinir la tarea universitaria transitando un recorrido que pretende ser inverso al tradicional; no se parte de conocimiento ya creado desde los paradigmas instituidos e institucionalizados académicamente sino que se comparte la creación de este saber desde los problemas científicos surgidos de las necesidades sociales existentes (Trinchero y Petz, 2014). Ese es el desafío y el cambio que conlleva este tipo de proyectos en contraposición al diseño más tradicional.

\section{Referencias bibliográficas}

Alonso, L. (2015). Prólogo. Informe de Gestión de la Subsecretaria de Coordinación de Políticas Universitarias. Ministerio de Educación.

Balazote, A. y Rotman, M. (2016). Marcas en la antropología argentina: el enfoque "fenomenológico", una perspectiva teórico-metodológica hegemónica en la historia de la disciplina. Antropologías del Sur, 3(6), $29-46$.

Bari, C. (2002). La cuestión étnica: aproximación a los conceptos de grupo étnico, identidad étnica, etnicidad y relaciones interétnicas. Cuadernos de Antropología Social, (16), 149-163.

Barrera, L. (2014). Burocracia y derecho. Reflexiones sobre el rol de los documentos en la construcción del conocimiento jurídico. Sociedad, (33), 73-90.

Bartolomé, M. (1997). Gente de costumbre y gente de razón. Las identidades étnicas en México. Siglo XXI Editores.

(2003). En defensa de la etnografía. El papel contemporáneo de la investigación intercultural. Revista de Antropología Social, (12), 199-222.

Bengoa, J. (2009). ¿Una segunda etapa de la Emergencia Indígena en América Latina? Cuadernos de Antropología Social, (29), 7-22. FFyL-UBA. 
Cardoso de Oliveira, R. (1998). O trabalho do antropólogo. Paralelo 15 y Editora Universidade Estadual Paulista. Castilla, M.; Varisco, S. y Valverde, S. (2018). Políticas de intervención con los pueblos originarios Mapuche y Qom en Argentina. Revista de Estudos e Pesquisas sobre as Américas, 12(2), 86-123.

Cervera Novo, J. P. (2018). ¿Qué es el CIDAC? en la sede del barrio de Barracas hay varias actividades, en esta nota, el coordinador general del centro nos cuenta un poco de la historia y del presente del CIDAC. C/DAC filo al sur, 1(1), 5-16.

Collinao, F.; Loncón, L.; Olivero, D.; Subiri, L.; Tropan, S.; Márquez, V.; Nahuel, F.; Ghioldi, G.; Trinchero, H.; Balazote, A.; Radovich, J. C.; Ramos, M.; de Jong, I.; Maragliano, G.; Impemba, M.; Stecher, G.; Valverde, S.; Varisco, S. y Pérez, A. (2019). Lof Paichil Antreao: comunidad mapuche ancestral de la región de Villa La Angostura. FFyL-UBA.

Engelman, J. M. (2011). Formas de organización social y liderazgo político en comunidades indígenas urbanas: estrategias de acceso al poder, construcción y mantenimiento en un caso de titulación y lucha por tierras comunitarias: Comunidad Tupí-Guaraní. Cacique Hipólito Yumbay. Tesis de Licenciatura. FFyL-UBA.

(2014). Etnicidades cuestionadas, metodología y epistemología de nucleamientos y comunidades indígenas urbanas. Polis, (38), 1-29.

_ (2017). Identidad étnica y práctica política al sur del conurbano bonaerense. Tesis de Doctorado. FFyLUBA.

Engelman, J.; Varisco, S.; Míguez, R. \& Weiss, M. L. (2018). Etnización de la práctica política de la dirigencia indígena en los gobiernos locales de la región metropolitana de Buenos Aires, Argentina. Antropologías del Sur, 5(9), 151-171.

Guiñazú, S. (2018). El interjuego entre la normalización estatal y agencia indígena en la ejecución del relevamiento territorial de comunidades indígenas en Río Negro, Argentina. Antropologías del Sur, 9(5), 173-197.

Halse, C. y Honey, A. (2007). Rethinking ethics review as institutional discourse. Qualitative Inquiry, 13(3), 336-352.

Lischetti, M. y Petz, I. (2019). Las prácticas socioeducativas, innovando trayectos desde la extensión universitaria. Redes de Extensión, (5), 1-6.

Maidana, C. (2019). La necesidad de conocimiento y reconocimiento plural. Los pueblos indígenas en la provincia de Buenos Aires, Argentina. Antropologías del sur, 6(11), 249-262.

Maragliano, G.; Impemba, M.; Stecher, G.; Valverde, S.; Balazote, A.; Berón, M.; Pérez, A. y Radovich, J. C. (2017). El prejuicio hacia el pueblo mapuce como supuestamente "chileno": una invención sumamente interesada y largamente refutada. Folleto PDTS-CIN-CONICET 252.

Mato, D. (2014). No "estudiar al subalterno ", sino estudiar con grupos sociales "subalternos", o, al menos, estudiar articulaciones hegemónicas de poder. Desafíos, 26(1), 237-264.

Míguez Palacio, R. (2016). Investigación y extensión universitaria. Reflexiones en torno al quehacer antropológico en comunidades indígenas urbanas. Cuadernos de Antropología Social, (15), 41-53.

Milanich, Nara (2009). Children of Fate: Childhood, Class, and the State in Chile, 1850- 1930. Duke University Press.

Nagy, M. (2013). Los museos de la última frontera bonaerense y sus narrativas acerca de los pueblos indígenas. Revista del Museo de Antropología, 6(1), 79-90.

Naidorf, J. y Perrota, D. (2015). La ciencia social politizada y móvil de una nueva agenda latinoamericana orientada a prioridades. Revista de la Educación Superior, 14(174). Asociación Nacional de Univseridades e Instituciones de Educación Superior de México.

Petz, I. (2015). Extensión universitaria: tendencias actuales y desafío pendientes. Redes de Extensión, (1), 1-5. - (2008). CIDAC: notas disparadoras para pensarnos en nuestra praxis. http://cidac.filo.uba.ar/biblioteca 
Petz, I.; Hindi, G.; Cervera Novo, J. P.; Corbato, G. y Giraudo, C. (2016). Sobre la construcción del derecho a la universidad en la Argentina de comienzos del siglo XXI. En Lischetti, M.; Petz, I. y Cueva, D. (Comps.), Las transformaciones de las universidades latinoamericanas en el marco de las políticas regionales de la última década. FFyL-UBA.

Quintupuray, L.; Quintupuray, C.; Quintupuray, E.; Quintupuray, M.; Arach, A.; Stecher, G. y Valverde, S. (2018). Informe histórico-antropológico del Lof Kintupuray del Lago Correntoso (inédito).mapas, otras territorialidades. Reflexiones a partir de experiencias de mapeo cultural participativo en Territorio Mapuche. । Jornadas Norpatagónicas de Experiencias Educativas en Ciencias Sociales para la Escuela Secundaria. II Jornadas Provinciales de Geografía, Ciencias Sociales y Educación (Neuquén). Instituto de Formación Docente Continua de Luis Beltrán.

Romero, C.; Valverde, S.; Engelman, J. M.; Weiss, M. L.; Pérez, A.; Süther, R. y Aurand, M. (2016). Educación y etnicidad. Comparación de experiencias indígenas e importancia del contexto educativo en el nivel medio y superior para la visibilización identitaria. En Mato, D. (Coord.), Educación Superior y Pueblos Indígenas en América Latina. Experiencias, interpelaciones y desafíos (pp. 335-355). Universidad Nacional de Tres de Febrero.

Segato, R. (2013). La crítica de la colonialidad en ocho ensayos. Y una antropología por demanda. Prometeo. Sociedad Argentina de Antropología (2019). Entrevista a Liliana Tamagno por Juan Carlos Radovich. Segundo ciclo de entrevistas de la Sociedad Argentina de Antropología. https://www.youtube.com/watch?$\mathrm{v}=940 \mathrm{~Tb} 3 \mathrm{YscO} 8$

Tamagno, L. (2014). Indígenas en la ciudad. Organización política en contextos de tensión entre patrimonio cultural y políticas públicas. En Tamagno, L. y Maffia, M. (Coords.), Indígenas, africanos y afrodescendientes en la Argentina. Convergencias, divergencias y desafíos (pp. 43-62). Biblos.

Tamagno, L.; García, S.; Ibáñez Castelli, M.; García, M.; Maidana, C.; Alaniz, M. y Solari Paz, V. (2005). Testigos y protagonistas: un proceso de construcción de conocimiento conjunto con vecinos Qom. Una forma de hacer investigación y extensión universitaria. Revista Argentina de Sociología, 3(5), 206-222.

Tipula, P. (2008). Metodología de mapeo territorial. Comunidades nativas Cocotaibo. Instituto del Bien Común. Tommasino, H. y Rodríguez, N. (2010). Tres tesis básicas sobre extensión y prácticas integrales en las 19 Universidades de la República. Cuadernos de extensión, (1), 19-39.

Trinchero, H. (2007). Aromas de lo Exótico (retornos del objeto). Para una crítica del objeto antropológico y sus modos de reproducción. SB, Colección Complejidad Humana.

Trinchero, H. y Petz, I. (2013). El academicismo interpelado. Sobre la experiencia de una modalidad de territorialización de la Universidad Pública y los desafíos que presenta. En Lischetti, M. (Coord.), Universidades latinoamericanas. Compromiso, praxis e innovación (pp. 143-165). FFyL-UBA.

(2014). La cuestión de la territorialización en las dinámicas de integración universidad-sociedad: Aportes para un debate sobre el "academicismo". Papeles de trabajo. Centro de Estudios Interdisciplinarios en Etnolingüistica y Antropología Socio-Cultural, (27), 142-160. Facultad de Humanidades y Artes, Universidad Nacional de Rosario.

Trinchero, H. \& Valverde, S. (2014). De la "guerra con el indio" a los pueblos originarios como sujetos sociales y políticos: del Centenario al Bicentenario argentino. En Trinchero, H.; Campos Muñoz, L. y Valverde, S. (Coords.), Pueblos indígenas, Estados nacionales y fronteras. Tensiones y paradojas de los procesos de transición contemporáneos en América Latina (pp. 175-222). FFyL-UBA.

Valverde, S. (2011). De "pobladores" a "mapuche": historias ausentes (y los ausentes de la historia). Papeles de trabajo. Centro de Estudios Interdisciplinarios en Etnolingüística y Antropología Socio-Cultural.

Valverde, S.; García, A. y Bersten, L. (2008). Relatos Patagónicos. Historias familiares en la construcción del espacio social en Villa Traful. Ferreyra Editor. 
Valverde, S.; Trentini, F.; Pérez, A. y Ghioldi, G. (2013). Volver al territorio: memorias mapuches en el Parque Nacional Nahuel Huapi. FFyL-UBA.

Varisco, S. (2020). La antropología mediada por el trabajo de investigación y de extensión universitaria. Cuadernos de Antropología. En prensa.

Varsavsky, O. (1969). Bases para una política nacional de tecnología y ciencia. En: Ciencia, política y cientificismo. Centro Editor de América Latina. Ponencia leída en la Facultad de Ingeniería de la UBA, diciembre de 1973. Weiss, M. L.; Engelman, J. \& Valverde, S. (2013). Pueblos indígenas urbanos en Argentina: un estado de la cuestión. Pilquen-Sección Ciencias Sociales, 16(1), 4-14.

Zenobi, D. (2019). El anonimato rebelde. Ética y conflicto en el trabajo de campo. Publicar, 17(25), 51-61.

\section{Otras fuentes}

Aranda, D. (27 de noviembre de 2017). Qué hay detrás de la campaña antimapuche. Lavaca org Cambio 2000 Online (1 de junio de 2017). Ceremonia Mapuche a orillas del Lago Epecuén. http://cambio2000. com.ar/pagina.php?id=20534

Diario La Mañana del Neuquén. (29 de diciembre de 2010). La Angostura tiene 11.087 personas. https://www. Imneuquen.com/la-angostura-tiene-11087-personas-n94000

Diario Río Negro (2 de mayo de 2013). Ratifican que Bariloche tiene 112.887 habitantes. https://www.rionegro, com.ar/region/ratifican-que-bariloche-tiene-112-887-habitan-DRRN_1154242

Guía para la inscripción en el Registro Provincial de Comunidades Indígenas. Anexo II de la Resolución 1/2016 del Consejo Provincial de Asuntos Indígenas —CPAl— con participación del Consejo Indígena de Buenos Aires_CIBA—). https://www.gba.gob.ar/derechoshumanos/consejos_provinciales

INDEC. Censo Nacional de Población, Hogares y Viviendas. Censo del Bicentenario No 2. Tomo I. Instituto Nacional de Estadística y Censos.

Reglamento de funcionamiento del Registro Provincial de Comunidades Indígenas (REPROCl). Consejo Provincial de Asuntos Indígenas (CPAI) Registro Provincial de Comunidades Indígenas (REPROCI) Anexo I - Resolución 1/16. https://www.gba.gob.ar/derechoshumanos/consejos_provinciales

Resolución 158/06. Funcionamiento CIBA. https://www.gba.gob.ar/derechoshumanos/consejos_provinciales 